\title{
Effectiveness of continuous positive airway pressure in lowering blood pressure in patients with obstructive sleep apnea: a critical review of the literature
}

Fernanda Fatureto-Borges'

Geraldo Lorenzi-Filho ${ }^{2}$

Luciano F Drager ${ }^{1,3}$

'Hypertension Unit, Heart Institute (InCor), ${ }^{2}$ Sleep Laboratory, Pulmonary Division, ${ }^{3}$ Hypertension Unit, Renal Division, University of Sao Paulo Medical School, Sao Paulo, Brazil
Correspondence: Luciano F Drager Hypertension Unit, Heart Institute (InCor), University of Sao Paulo Medical School, Avenida Doutor Eneas Carvalho de Aguiar, 44, 05403-904 Sao Paulo, Brazil Email luciano.drager@incor.usp.br

\author{
This article was published in the following Dove Press journal: \\ Integrated Blood Pressure Control \\ 15 March 2016 \\ Number of times this article has been viewed
}

\begin{abstract}
Obstructive sleep apnea (OSA) is an extremely common comorbid condition in patients with hypertension, with a prevalence of $\sim 50 \%$. There is growing evidence suggesting that OSA is a secondary cause of hypertension, associated with both poor blood pressure (BP) control and target organ damage in patients with hypertension. The application of continuous positive airway pressure (CPAP) during sleep is the gold standard treatment of moderateto-severe OSA and very effective in abolishing obstructive respiratory events. However, several meta-analyses showed that the overall impact of CPAP on BP is modest ( $2 \mathrm{mmHg})$. There are several potential reasons for this disappointing finding, including the heterogeneity of patients studied (normotensive patients, controlled, and uncontrolled patients with hypertension), nonideal CPAP compliance, clinical presentation (there is some evidence that the positive impact of CPAP on lowering BP is more evident in sleepy patients), and the multifactorial nature of hypertension. In this review, we performed a critical analysis of the literature evaluating the impact of CPAP on BP in several subgroups of patients. We finally discussed perspectives in this important research area, including the urgent need to identify predictors of BP response to CPAP and the importance of precision medicine in this scenario.
\end{abstract}

Keywords: cardiovascular disease, CPAP, hypertension, sleep apnea, treatment

\section{Introduction}

Obstructive sleep apnea (OSA) is a major public health issue characterized by repetitive episodes of partial or total occlusion of the upper airway during sleep, causing exaggerated effort to breathe against the occluded airway, sleep fragmentation, and intermittent hypoxia. ${ }^{1}$ The effects of OSA during sleep (especially intermittent hypoxia) elicit a number of intermediate mechanisms, including sympathetic activation, endothelial dysfunction, oxidative stress, inflammation, and metabolic dysfunction, which can contribute to increased cardiovascular risk. ${ }^{2}$

OSA is a common condition in the general population, ${ }^{3}$ particularly in patients with cardiovascular disease. ${ }^{2}$ For instance, in patients with hypertension, the frequency of OSA is $\sim 50 \%{ }^{4}$ Among patients with resistant hypertension $(\mathrm{RH})$, the prevalence of OSA varies from $64 \%$ to $83 \% \%^{5,6}$ depending on the cutoff used for OSA definition. Other than a common condition in patients with hypertension, there is a growing evidence indicating that OSA is associated with increased arterial stiffness, ${ }^{7}$ heart remodeling, ${ }^{7}$ and impaired blood pressure (BP) control in patients with hypertension. ${ }^{8}$ 
In this review, we discussed the effectiveness of the main treatment for OSA, namely continuous positive airway pressure (CPAP), in lowering BP in patients with OSA. Particularly, we performed a critical analysis of the literature evaluating the impact of CPAP on BP in several subgroups of patients. We finally discussed perspectives in this important research area, including the urgent need to identify feasible predictors of BP response to CPAP.

\section{Impact of CPAP on normotensive patients and critical evaluation of meta-analysis}

A few studies that were designed to evaluate the cardiovascular impact of treating OSA independent of the effects on $\mathrm{BP}$ are instructive to the field. For instance, we performed a randomized study to evaluate the impact of CPAP on early markers of atherosclerosis and arterial stiffness in normotensive patients with severe OSA. ${ }^{9}$ Patients with severe OSA were optimally treated with CPAP (compliance $\sim 6$ hours/ night) for 4 months, resulting in a significant decrease in catecholamines, C-reactive protein, pulse-wave velocity, and carotid intima-media thickness. ${ }^{9}$ In contrast, BP did not change significantly, suggesting that the protective effects of OSA treatment on preventing cardiovascular disease ${ }^{10}$ are not necessarily mediated through BP reduction. Faccenda et al explored the impact of CPAP on patients under no medications that had a baseline BP close to the normal range. ${ }^{11}$ The authors found very modest effects of CPAP on BP that was limited to a modest decrease in diastolic BP. Taken together, these studies clearly showed that the impact of OSA treatment with CPAP on patients who have normal BP at study entry seems to be very limited or nonexistent. Despite this fundamental concept, several randomized studies designed to evaluate the impact of the treatment of OSA on BP included normotensive patients at study entry. ${ }^{12-14}$ Consequently, the meta-analysis evaluating the impact of CPAP on BP was clearly influenced by such heterogeneity. ${ }^{12-14}$ Therefore, the modest effects of CPAP on BP drop $(\sim 2 \mathrm{mmHg})$ may partially be explained by including normotensive patients or hypertensive patients who had well-controlled BP at the start of the study due to a number of different antihypertensive medications.

\section{Effects of CPAP on OSA patients with prehypertension and masked hypertension and on the prevention of sustained hypertension}

Prehypertension (defined as a systolic BP of 120-139 mmHg and diastolic BP of $80-89 \mathrm{mmHg}$ ) and masked hypertension (defined by normal office BP and abnormal 24-hour ambulatory BP) are precursors of sustained hypertension and cardiovascular events. ${ }^{15,16}$ Of note, masked hypertension is frequently observed in patients with OSA. ${ }^{17,18}$ Based on these concepts, it is reasonable to speculate that patients with prehypertension and/or masked hypertension who also have OSA may benefit from CPAP treatment. To test this hypothesis, we performed a randomized study to evaluate the impact of CPAP on patients with severe OSA with diagnostic criteria for prehypertension and/or masked hypertension, based on the office and 24-hour ambulatory BP monitoring, respectively. ${ }^{19}$ Patients were randomized to no treatment or CPAP for 3 months. They had similar frequency of prehypertension and masked hypertension at study entry. There were no significant changes in BP in patients randomized to the control group. In contrast, patients randomized to CPAP presented $5 \mathrm{mmHg}$ reduction in office systolic $\mathrm{BP}$ and $4 \mathrm{mmHg}$ reduction in diastolic BP. We observed a significant reduction in the frequency of prehypertension (from $94 \%$ to $55 \% ; P=0.02$ ) and masked hypertension (from $39 \%$ to $5 \% ; P=0.04$ ) only in the CPAP group. ${ }^{19} \mathrm{~A}$ recent study confirmed the impact of CPAP on BP in OSA patients with prehypertension. ${ }^{20}$ These results suggested that early identification and treatment of OSA in apparently healthy, normotensive individual may prevent the development of hypertension. This hypothesis was explored by a multicentric study conducted in Spain. ${ }^{21}$ A prospective cohort study of 1,889 participants without hypertension who were referred to a sleep center was used to calculate hazard ratios (HRs) of incident hypertension in participants without OSA (controls) and with untreated OSA and in those treated with CPAP therapy. Compared to controls, the adjusted HRs for incident hypertension were greater in patients with OSA ineligible for CPAP therapy (HR: 1.33), in those who declined CPAP therapy (HR: 1.96), and in those nonadherent to CPAP therapy (HR: 1.78), whereas the HR was lower in patients with OSA who were treated with CPAP therapy $(0.71) .{ }^{21}$

\section{Impact of CPAP on patients with OSA with non-RH}

As previously discussed, the impact of OSA treatment on $\mathrm{BP}$ is mitigated by the inclusion of normotensive patients or those who had controlled BP at study entry. Moreover, as highlighted by at least one recent meta-analysis, ${ }^{14}$ several studies mixed normotensive and hypertensive patients. In this scenario, it is impressive that there are not too many randomized studies comprising $100 \%$ of hypertension patients with OSA. These studies ${ }^{22-27}$ (detailed in a recent review ${ }^{28}$ ) found a modest reduction in BP only in half of the studies. Pépin et $\mathrm{al}^{24}$ highlighted that the effects of antihypertensive drugs, such as valsartan, were greater than those of CPAP, 
although when used in combination with CPAP, the two treatments appeared to have significant additive effects on BP. In hypertensive patients with coronary artery disease, a recent randomized study showed that $\mathrm{BP}$ in the CPAP group decreased by $8 \mathrm{mmHg} .{ }^{29}$ As a consequence, hypertension control (defined as resting BP $<140 / 90$ or $<130 / 80 \mathrm{mmHg}$ in patients with diabetes) was higher in the CPAP group. However, diastolic BP did not reach statistical difference between the groups.

An intriguing result is the effect of CPAP on BP in nonsleepy/minimally symptomatic patients with OSA. A recent meta-analysis comprising individual data found that CPAP has no overall beneficial effect on BP in patients with minimally symptomatic OSA..$^{30}$ Interestingly, the authors found an increase in systolic BP in patients using CPAP $<4$ hours/ night (1.5 mmHg, $95 \%$ confidence interval [CI]: -0.0 to 3.1 , $P=0.052)$ and reduction in diastolic BP in patients using CPAP $>4$ hours/night $(-1.4 \mathrm{mmHg}, 95 \% \mathrm{CI}:-2.5$ to $-0.4, P=0.008)$. The precise reasons for these findings are not clear.

\section{Impact of CPAP on OSA patients with RH}

Several studies explored the impact of OSA treatment with CPAP on patients with RH. After impressive results derived from nonrandomized investigations (observing $\geq 10 \mathrm{mmHg}$ drop after CPAP), ${ }^{31}$ six randomized trials came up so far. ${ }^{32-37}$ All but one study found significant reductions in BP. A recent meta-analysis including only randomized studies found that the pooled changes after CPAP treatment for 24-hour ambulatory systolic BP and diastolic BP were $-4.78 \mathrm{mmHg}$ (95\% CI: -7.95 to -1.61$)$ and $-2.95 \mathrm{mmHg}(95 \% \mathrm{CI}:-5.37$ to -0.53$)$ in favor of the CPAP group. ${ }^{38}$ These results suggest that among patients with OSA, those who also have RH are the best responders in terms of BP drop after CPAP treatment.

\section{Conclusion and perspectives}

OSA is commonly observed in patients with hypertension, especially in the subgroup of RH. However, OSA is still underdiagnosed in patients with cardiovascular disease, including hypertension. ${ }^{39}$ As discussed in this review, the overall impact of CPAP on BP is modest (Table 1), but even small reductions in BP may have impact on preventing cardiovascular events. ${ }^{40}$ Based on our previous comments, despite several studies already evaluated BP response to CPAP, there is still room for new studies addressing this effect on patients with uncontrolled hypertension. Another opportunity in this research area is the observed high variability of BP response to CPAP treatment. It is well known that good CPAP adherence is associated with greater BP
Table I Summary of BP effects of CPAP on patients with OSA derived from randomized studies ${ }^{\mathrm{a}}$

\begin{tabular}{|c|c|c|}
\hline Patients' profile & $\begin{array}{l}\text { BP effects } \\
\text { of CPAP }\end{array}$ & Comments \\
\hline Normotensive $e^{9,11}$ & $\begin{array}{l}\text { No or very } \\
\text { mild effect }\end{array}$ & $\begin{array}{l}\text { BP is already optimal and } \\
\text { any intervention may have } \\
\text { a minimal or neutral effect } \\
\text { on BP levels }\end{array}$ \\
\hline $\begin{array}{l}\text { Prehypertension/ } \\
\text { masked hypertension }{ }^{19}\end{array}$ & Mild effect & $\begin{array}{l}\text { One small randomized } \\
\text { trial showed } 5 \mathrm{mmHg} \\
\text { drop in systolic BP } \\
\text { after CPAP and a } \\
\text { significant reduction } \\
\text { in the frequency of } \\
\text { prehypertension and } \\
\text { masked hypertension in } \\
\text { patients with severe } \\
\text { OSA } \\
\text { - More randomized trials } \\
\text { are needed }\end{array}$ \\
\hline $\begin{array}{l}\text { Controlled } \\
\text { hypertensives } 22,23,26\end{array}$ & $\begin{array}{l}\text { No or } \\
\text { modest } \\
\text { effect }\end{array}$ & $\begin{array}{l}\text { - Results are variable } \\
\text { - No ideal CPAP } \\
\text { compliance in some } \\
\text { studies }\end{array}$ \\
\hline $\begin{array}{l}\text { Uncontrolled } \\
\text { hypertensives (with } \\
\text { or without resistant } \\
\text { hypertension } \\
\text { diagnosis) }{ }^{24,25,27,29}\end{array}$ & $\begin{array}{l}\text { Modest effect } \\
(\sim 2 \mathrm{mmHg})\end{array}$ & $\begin{array}{l}\text { - Results are variable } \\
\text { (from no effect to } \\
8 \mathrm{mmHg} \text { drop in BP) } \\
\text { - The effects seem to be } \\
\text { more evident in sleepy } \\
\text { patients } \\
\text { - No ideal CPAP } \\
\text { compliance in some } \\
\text { studies } \\
\text { - More randomized trials } \\
\text { are needed }\end{array}$ \\
\hline $\begin{array}{l}\text { Resistant } \\
\text { hypertension }^{32-37}\end{array}$ & $\begin{array}{l}\text { Mild effect } \\
(3-5 \mathrm{mmHg})\end{array}$ & $\begin{array}{l}\text { - Only one study showed no } \\
\text { effect on BP36 } \\
\text { - Results are variable } \\
\text { (from no effect to } \\
10 \mathrm{mmH} \text { g drop in } \mathrm{BP}) \text {. } \\
\text { Overall, the proportion } \\
\text { of patients who reach BP } \\
\text { goal }(<140 / 90 \mathrm{mmHg} \text { ) } \\
\text { is low } \\
\text { - A recent report found } \\
\text { biomarkers of BP } \\
\text { response to CPAP in } \\
\text { patients with good device } \\
\text { adherence }{ }^{41}\end{array}$ \\
\hline
\end{tabular}

Note: ${ }^{\mathrm{a}}$ This table does not contain randomized studies that mixed normotensive and hypertensive patients.

Abbreviations: $\mathrm{BP}$, blood pressure; CPAP, continuous positive airway pressure; OSA, obstructive sleep apnea.

response. However, even good CPAP users may have small effects on BP. In this regard, there is an increasing interest in exploring biomarkers to identify those who will respond favorably to CPAP. This personalized medicine approach 
was recently explored in a subset of patients with OSA and RH enrolled in the HIPARCO study. ${ }^{34}$ The authors measured microRNA (miRNA) expression in plasma samples using an 84-miRNA array in patients with RH and OSA at baseline and after 3 months of adherent CPAP use (at least 4 hours/night). ${ }^{41}$ Two subgroups of patients were studied: OSA responders $(>4.5 \mathrm{mmHg})$ and nonresponders $(\leq 4.5 \mathrm{mmHg})$. Three miRNAs provided a discriminatory predictive model for such a favorable BP response to CPAP (miR-378a-3p, miR-486-5p, and miR-100-5p). Additionally, CPAP treatment significantly altered a total of 47 plasma miRNAs and decreased aldosterone-to-renin ratios in the responder group ( $P=0.016$ ) but not in the nonresponder group. ${ }^{41}$ Further studies are needed to elucidate the mechanisms mediating the relationship between these miRNAs and other potential biomarkers in response to CPAP.

\section{Disclosure}

The authors report no conflicts of interest in this work.

\section{References}

1. Sleep-related breathing disorders in adults: recommendations for syndrome definition and measurement techniques in clinical research. The Report of an American Academy of Sleep Medicine Task Force. Sleep. 1999;22(5):667-669.

2. Drager LF, Togeiro SM, Polotsky VY, Lorenzi-Filho G. Obstructive sleep apnoea: a cardiometabolic risk in obesity and the metabolic syndrome. J Am Coll Cardiol. 2013;62(7):569-576.

3. Peppard PE, Young T, Barnet JH, Palta M, Hagen EW, Hla KM. Increased prevalence of sleep-disordered breathing in adults. Am J Epidemiol. 2013;177(9):1006-1014.

4. Drager LF, Genta PR, Pedrosa RP, et al. Characteristics and predictors of obstructive sleep apnea in patients with systemic hypertension. Am J Cardiol. 2010;105(8):1135-1139.

5. Logan AG, Perlikowski SM, Mente A, et al. High prevalence of unrecognized sleep apnoea in drug-resistant hypertension. $J$ Hypertens. 2001;19(12):2271-2277.

6. Pedrosa RP, Drager LF, Gonzaga CC, et al. Obstructive sleep apnea: the most common secondary cause of hypertension associated with resistant hypertension. Hypertension. 2011;58(5):811-817.

7. Drager LF, Bortolotto LA, Figueiredo AC, Silva BC, Krieger EM, Lorenzi-Filho G. Obstructive sleep apnea, hypertension, and their interaction on arterial stiffness and heart remodeling. Chest. 2007;131(5):1379-1386.

8. Ancoli-Israel S, Stepnowsky C, Dimsdale J, Marler M, Cohen-Zion M, Johnson S. The effect of race and sleep-disordered breathing on nocturnal BP "dipping": analysis in an older population. Chest. 2002;122(4):1148-1155.

9. Drager LF, Bortolotto LA, Figueiredo AC, Krieger EM, Lorenzi GF. Effects of continuous positive airway pressure on early signs of atherosclerosis in obstructive sleep apnea. Am J Respir Crit Care Med. 2007;176(7):706-712.

10. Marin JM, Carrizo SJ, Vicente E, Agusti AG. Long-term cardiovascular outcomes in men with obstructive sleep apnoea-hypopnoea with or without treatment with continuous positive airway pressure: an observational study. Lancet. 2005;365(9464):1046-1053.

11. Faccenda JF, Mackay TW, Boon NA, Douglas NJ. Randomized placebo controlled trial of continuous positive air pressure in the sleep apneahypopnea syndrome. Am J Respir Crit Care Med. 2001;163:344-388.
12. Bazzano LA, Khan Z, Reynolds K, He J. Effect of nocturnal nasal continuous positive airway pressure on blood pressure in obstructive sleep apnea. Hypertension. 2007;50(2):417-423.

13. Haentjens P, Van Meerhaeghe A, Moscariello A, et al. The impact of continuous positive airway pressure on blood pressure in patients with obstructive sleep apnea syndrome: evidence from a metaanalysis of placebo-controlled randomized trials. Arch Intern Med. 2007;167(8):757-764.

14. Fava C, Dorigoni S, Dalle Vedove F, et al. Effect of CPAP on blood pressure in patients with OSA/hypopnea a systematic review and metaanalysis. Chest. 2014;145(4):762-771.

15. Vasan RS, Larson MG, Leip EP, et al. Impact of high-normal blood pressure on the risk of cardiovascular disease. $N$ Engl J Med. 2001;345:1291-1297.

16. Pickering TG, Eguchi K, Kario K. Masked hypertension: a review. Hypertens Res. 2007;30:479-488.

17. Baguet JP, Lévy P, Barone-Rochette G, et al. Masked hypertension in obstructive sleep apnea syndrome. J Hypertens. 2008;26(5):885-892.

18. Drager LF, Diegues-Silva L, Diniz PM, et al. Obstructive sleep apnea, masked hypertension, and arterial stiffness in men. Am J Hypertens. 2010;23(3):249-254.

19. Drager LF, Pedrosa RP, Diniz PM, et al. The effects of continuous positive airway pressure on prehypertension and masked hypertension in men with severe obstructive sleep apnea. Hypertension. 2011;57(3):549-555.

20. Yorgun H, Kabakçi G, Canpolat U, et al. Predictors of blood pressure reduction with nocturnal continuous positive airway pressure therapy in patients with obstructive sleep apnea and prehypertension. Angiology. 2014;65(2):98-103.

21. Marin JM, Agusti A, Villar I, et al. Association between treated and untreated obstructive sleep apnea and risk of hypertension. JAMA. 2012;307(20):2169-2176.

22. Campos-RodriguezF, Grilo-Reina A, Perez-Ronchel J, Merino-Sanchez M. Effect of continuous positive airway pressure on ambulatory BP in patients with sleep apnea and hypertension: a placebo-controlled trial. Chest. 2006;129(6):1459-1467.

23. Nguyen PK, Katikireddy CK, McConnell MV, Kushida C, Yang PC. Nasal continuous positive airway pressure improves myocardial perfusion reserve and endothelial-dependent vasodilation in patients with obstructive sleep apnea. J Cardiovasc Magn Reson. 2010;12(0):50.

24. Pépin JL, Tamisier R, Barone-Rochette G, Launois SH, Lévy P, Baguet JP. Comparison of continuous positive airway pressure and valsartan in hypertensive patients with sleep apnea. Am J Respir Crit Care Med. 2010;182(7):954-960.

25. Robinson GV, Smith DM, Langford BA, Davies RJ, Stradling JR. Continuous positive airway pressure does not reduce blood pressure in nonsleepy hypertensive OSA patients. Eur Respir J. 2006;27(6):1229-1235.

26. Durán-Cantolla J, Aizpuru F, Montserrat JM, et al; Spanish Sleep and Breathing Group. Continuous positive airway pressure as treatment for systemic hypertension in people with obstructive sleep apnoea: randomised controlled trial. BMJ. 2010;341:c5991.

27. Barbé F, Durán-Cantolla J, Capote F, et al; Spanish Sleep and Breathing Group. Long-term effect of continuous positive airway pressure in hypertensive patients with sleep apnea. Am J Respir Crit Care Med. 2010;181(7):718-726.

28. Furlan SF, Braz CV, Lorenzi-Filho G, Drager LF. Management of hypertension in obstructive sleep apnea. Curr Cardiol Rep. 2015; 17(12): 108 .

29. Huang Z, Liu Z, Luo Q, et al. Long-term effects of continuous positive airway pressure on blood pressure and prognosis in hypertensive patients with coronary heart disease and obstructive sleep apnea: a randomized controlled trial. Am J Hypertens. 2015;28(3):300-306.

30. Bratton DJ, Stradling JR, Barbé F, et al. Effect of CPAP on blood pressure in patients with minimally symptomatic obstructive sleep apnoea: a meta-analysis using individual patient data from four randomised controlled trials. Thorax. 2014;69(12):1128-1135. 
31. Logan AG, Tkacova R, Perlikowski SM, et al. Refractory hypertension and sleep apnoea: effect of CPAP on blood pressure and baroreflex. Eur Respir J. 2003;21(2):241-247.

32. Lozano L, Tovar JL, Sampol G, et al. Continuous positive airway pressure treatment in sleep apnea patients with resistant hypertension: a randomized, controlled trial. J Hypertens. 2010;28(10):2161-2168.

33. Pedrosa RP, Drager LF, de Paula LK, Amaro AC, Bortolotto LA, Lorenzi-Filho G. Effects of obstructive sleep apnea treatment on blood pressure in patients with resistant hypertension: a randomized trial. Chest. 2013;144(5):1487-1494.

34. Martínez-García MA, Capote F, Campos-Rodríguez F, et al; Spanish Sleep Network. Effect of CPAP on blood pressure in patients with obstructive sleep apnea and resistant hypertension: the HIPARCO randomized clinical trial. JAMA. 2013;310(22):2407-2415.

35. de Oliveira AC, Martinez D, Massierer D, et al. The antihypertensive effect of positive airway pressure on resistant hypertension of patients with obstructive sleep apnea: a randomized, double-blind, clinical trial. Am J Respir Crit Care Med. 2014;190(3):345-347.

36. Muxfeldt ES, Margallo V, Costa LM, et al. Effects of continuous positive airway pressure treatment on clinic and ambulatory blood pressures in patients with obstructive sleep apnea and resistant hypertension: a randomized controlled trial. Hypertension. 2015;65(4):736-742.
37. Litvin AY, Sukmarova ZN, Elfimova EM, et al. Effects of CPAP on "vascular" risk factors in patients with obstructive sleep apnea and arterial hypertension. Vasc Health Risk Manag. 2013;9(0):229-235.

38. Liu L, Cao Q, Guo Z, Dai Q. Continuous positive airway pressure in patients with obstructive sleep apnea and resistant hypertension: a metaanalysis of randomized controlled trials. J Clin Hypertens (Greenwich). Epub 2015 Aug 17.

39. Costa LE, Uchôa CH, Harmon RR, Bortolotto LA, Lorenzi-Filho G, Drager LF. Potential underdiagnosis of obstructive sleep apnoea in the cardiology outpatient setting. Heart. 2015;101:1288-1292.

40. Turnbull F. Effects of different blood-pressure-lowering regimens on major cardiovascular events: results of prospectively-designed overviews of randomized trials. Lancet. 2003;362:1527-1535.

41. Sánchez-de-la-Torre M, Khalyfa A, Sánchez-de-la-Torre A, et al; Spanish Sleep Network. Precision medicine in patients with resistant hypertension and obstructive sleep apnea: blood pressure response to continuous positive airway pressure treatment. J Am Coll Cardiol. 2015;66(9):1023-1032.
Integrated Blood Pressure Control

\section{Publish your work in this journal}

Integrated Blood Pressure Control is an international, peer-reviewed open-access journal focusing on the integrated approach to managing hypertension and risk reduction. Treating the patient and comorbidities together with diet and lifestyle modification and optimizing healthcare resources through a multidisciplinary team approach constitute key

\section{Dovepress}

features of the journal. This journal is indexed on American Chemical Society's Chemical Abstracts Service (CAS). The manuscript management system is completely online and includes a very quick and fair peerreview system, which is all easy to use. Visit http://www.dovepress.com/ testimonials.php to read real quotes from published authors.

Submit your manuscript here: http://www.dovepress.com/integrated-blood-pressure-control-journal 